\title{
Review of: "Hypoxia-inducible factor $1 \alpha$ induces osteo/odontoblast differentiation of human dental pulp stem cells via Wnt/ $\beta$-catenin transcriptional cofactor BCL9"
}

\section{Hidefumi Maeda ${ }^{\mathrm{T}}$}

1 Kyushu University

Potential competing interests: The author(s) declared that no potential competing interests exist.

This is an excellent report to clarify the mechanism of mineralization of dental pulp tissue observed after the trauma upon this tissue, caused by avulsion or luxation of tooth. Authors focused on the influence of hypoxia on the tissue in this situation. Subsequently they indicated the involvement of HIF1 $\alpha / B C L 9$ and Wnt signalings in its healing. So these findings will help to develop the new therapeutic approach to avoid this excess mineralization and preserve healthy pulp tissue. 